\title{
Analysis of Bamboo Fibre Reinforced Beam
}

\section{Bashir A ${ }^{1}$, Gupta $C^{1}$, Abubakr MA ${ }^{2}$ and Abba S13*}

${ }^{1}$ Department of Civil Engineering, Sharda University, India

${ }^{2}$ Deptartment of Civil Engineering, Ministry of Works and Housing Kano State, Nigeria

${ }^{3}$ Kano PPD\&M Department, Yusuf Maitama Sule University, Nigeria

\begin{abstract}
Concrete is a widely utilized development material for its different points of interest, for example, ease, accessibility, imperviousness to fire and so on. Be that as it may, it can't be utilized alone wherever as a result of its low rigidity. Along these lines, by and large steel is utilized to strengthen the solid. Be that as it may, considering mind-boggling expense of steel, bamboo is one of the appropriate substitutions of fortifying bar in concrete for ease developments. Bamboo is regular, shabby, generally accessible and above all solid in both pressure and pressure. To see the impact of bamboo fiber on compressive and flexure quality, bamboo fortified Concrete 3D shapes have been tried. Assist separately fortified and plain bars with bamboo strands have been thrown and tried in flexure. It has been discovered that there is amazingly diminish in the flexural quality and Modulus of flexibility of bamboo strengthened shaft. The solid 3D squares and pillars were fortified with changing level of bamboo filaments of size $(25 \mathrm{~mm} \times 7 \mathrm{~mm}$ $\times 3 \mathrm{~mm}$ ), the rates being $0 \%, 0.5 \%, 1 \%, 1.5 \%$, and $2 \%$ concerning the volume of $3 \mathrm{D}$ shapes and additionally shafts. When the compression tests were performed the compressive strength of the concrete cubes were found to have increased remarkably with increase in the percentage of the bamboo fibers. As such we can utilize the naturally bamboo materials by making them into fibers and use them in increasing the compressive strength of concrete structures thereby reducing the environmental pollution caused by the bamboo when left unused.
\end{abstract}

Keywords: Bamboo; Reinforcement; Concrete; Compressive strength; Flexural strength

\section{Introduction}

In many nations, concrete is broadly utilized as the establishment for the framework. Concrete is utilized to a great extent since it is prudent, promptly accessible and has appropriate building properties, for example, its capacity to help vast compressive burdens. In any case, the utilization of cement is restricted in light of the fact that it has low rigidity. Therefore, it is fortified, and one of the more prevalent fortifying bars (rebar) is steel. Steel has a moderately high elasticity, as high as $115 \mathrm{ksi}\left(792 \mathrm{~N} / \mathrm{mm}^{2}\right)$, supplementing the low rigidity of cement. It is accessible and moderate in most created nations yet lamentably not all parts of the world. In numerous nations, none or almost no steel support is utilized as a part of development, which is obvious from the disintegrating of buildings. Steel fortification sooner or later may never again be accessible. Indeed, even today there exists a requirement for more practical and promptly accessible substitute fortifications for concrete. In a few sections of the world numerous structures are built just with cement or mud-blocks. This is risky if there should arise an occurrence of seismic action. These structures have little any desire for remaining on account of a tremor. Steel fortification would be a perfect arrangement, yet cost is an impressive issue. Researchers and designers are always looking for new materials for basic frameworks; utilizing bamboo as conceivable fortification has picked up notoriety.

\section{Reviews on bamboo}

Bamboo is goliath grass, not a tree. Bamboo culms are a barrel shaped shell partitioned by strong transverse stomachs at hubs and make them captivating properties, for example, high quality toward the path parallel to the strands, which run longitudinally along the length of the culm, and low quality toward a path opposite to the filaments. The thickness of strands in cross-area of a bamboo shell changes with thickness and in addition tallness. Fiber appropriation is more uniform at the base than at the best or the center. This is on account of bamboo is subjected to greatest twisting worry because of twist at the best part of the culm [1] Bamboo is a characteristic Functionally
Graded Material (FGM). It is a composite with progressive structure. The quality of bamboo is more noteworthy than a large portion of the timber products. The mechanical properties change with tallness and age of the bamboo culm. Research discoveries show that the quality of bamboo increments with age. The ideal quality esteem happens somewhere in the range of 2.5 and 4 years. The quality abatements at a later age [2-15]. The capacity of the hubs is to counteract clasping and they assume a part of pivotal split arresters. One noteworthy issue with bamboo is that it is a living life form which is liable to organisms and creepy crawly assaults. Bamboo is more inclined to creepy crawly assault than different trees and grasses due to its high substance of supplements. With a specific end goal to battle this issue, it ends up important to treat the bamboo to shield it from the earth. One of the astonishing parts of bamboo is the manner in which it collaborates with the earth. It has been found that bamboo can avert contamination by engrossing a lot of nitrogen from squander water and lessening the measure of carbon dioxide noticeable all around [3]. Bamboo achieves its full development in only a couple of months and achieves its most extreme mechanical quality in only couple of years. Its wealth in tropical and subtropical locales makes it a financially profitable material. A portion of the positive perspectives, for example, a lightweight plan, better adaptability, and sturdiness because of its thin dividers with discretely dispersed hubs and its incredible quality make it a decent development material. Bamboo is utilized as auxiliary material for platform at building locales in India, China and different nations as it is an intense, adaptable, light weight and ease material. In nature when

*Corresponding author: Abba SI; Kano PPD\&M Department, Yusuf Maitama Sule University, Nigeria; Tel: +2347014814105; E-mail: abbabashir2010@gmail.com

Received August 13, 2018; Accepted August 16, 2018; Published August 24 2018

Citation: Bashir A, Gupta C, Abubakr MA, Abba SI (2018) Analysis of Bamboo Fibre Reinforced Beam. J Steel Struct Constr 4: 146. doi: 10.4172/2472-0437.1000146

Copyright: @ 2018 Bashir A, et al. This is an open-access article distributed under the terms of the Creative Commons Attribution License, which permits unrestricted use, distribution, and reproduction in any medium, provided the original author and source are credited. 
bamboo is secured with substantial snow, it will twist until the point when it contacts the ground without breaking. This infers bamboo has more noteworthy adaptability than wood. "The vitality important to deliver $1 \mathrm{~m}^{3}$ for every unit stretch anticipated by and by for materials ordinarily utilized as a part of common development, for example, steel or cement, has been contrasted and bamboo. It was discovered that for steel it is important to burn through 50 times more vitality than for bamboo". The elasticity of bamboo is high and can reach $54 \mathrm{ksi}(370 \mathrm{~N} /$ $\mathrm{mm}^{2}$ ). This makes bamboo an other option to steel in ductile stacking applications. This is because of the way that the proportion of elasticity to particular weight of bamboo is six times more noteworthy than that of steel [4].

Bamboo has been and is being utilized as a part of a wide assortment of utilizations, for example, amusement, safeguard, lodging and development. With respect to entertainment bamboo has been utilized to build an assortment of melodic instruments. Notwithstanding the way that bamboo can be utilized as a part of expressions of the human experience, it can likewise be eaten. The market for bamboo shoots has developed quickly in the most recent years. Truth be told Taiwan trades $\$ 50$ million dollars worth of shoots that are eaten around the world. One of the real utilizations of bamboo is for development and lodging. It is assessed that one billion individuals live in bamboo houses. It can likewise be utilized to make furniture. Over a time of multi year the fares of bamboo furniture relatively multiplied in Philippines. In India and China bamboo is utilized as a part of development of impermanent suspension spans. In Tokyo and Hong Kong it is utilized as platform in elevated structures. Bamboo can likewise be utilized as a part of human expressions. It can be formed into numerous shapes prompting aesthetic opportunity as bamboo has been made into furniture, enriching things, for example, home adornment, dishware, dolls, toys, gems and that's only the tip of the iceberg. The creative energy goes on everlastingly thus does the artist. Bamboo is additionally a well known device for getting nourishment: as bamboo angling bars have been utilized to get angle for long time. In prior circumstances, bamboo could be utilized as a limit weapon, or it could be honed to give sustenance or barrier. It would likewise make an OK shaft for a lance. Indeed, even in the US, bamboo is starting to pick up presentation as deck and paneling. There are organizations that make compressed wood out of bamboo called utilize boo.

\section{Comparison of bamboo and steel}

One of the properties that would make bamboo a decent substitute to steel in strengthened cement is its quality. The quality of bamboo is more prominent than most timber items which are favorable, yet it is around a large portion of the rigidity of steel. Bamboo is effortlessly open as it develops in relatively every tropical and subtropical locale, this brings down the cost of development and expands the quality of the structures that would somehow or another be unreinforced. One noteworthy issue with bamboo is that it draws in living being, for example, growths and creepy crawlies. Bamboo is more inclined to creepy crawlies than different trees and grasses since it has a high substance of supplements. With a specific end goal to battle this issue, it winds up important to treat bamboo to shield it from the earth. Steel does not have this issue but rather it additionally should be covered keeping in mind the end goal to shield it from rusting. Bamboo is light in weight contrasted with steel. Because of its low modulus of versatility, bamboo can split and redirect more than steel fortification under similar conditions. These perspectives put bamboo on the rundown of feasible development materials. These properties, when joined, propose that bamboo will make a fine expansion to the present determination of materials, yet it is vital that individuals as a rule be made more comfortable with its qualities and shortcomings.

\section{Experimental Programs}

\section{Material testing}

Specific gravity of fine aggregate: This test is conducted using a picnometer. $500 \mathrm{~g}$ of the sample was taken and the picnometer was fill to the brink with water. The fine aggregate sample was put into the picnometer filled with water, the weight of the displaced water was measured and found to be $195 \mathrm{~g}$. The specific gravity of the fine aggregate was found by dividing the weight of the fine aggregate sample to the weight of displaced water from the picnometer. The aim of the experiment was to find out the density of the fine sand and it was found out to be 2.56 .

Specific gravity of coarse aggregate: This test was conducted using a specific gravity apparatus. The coarse aggregate washed, dried for 24 hours to remove moisture. The weight of the aggregate was measured before immersing it in water and found to be $4 \mathrm{~kg}$. The weight of the aggregate water was measured when immersed in water and found to be $2.375 \mathrm{~kg}$.

$$
\begin{aligned}
& \text { Weight of water }=42.375 \\
& \mathrm{~W}_{\text {WATER }}=1.625 \mathrm{~kg} \\
& \text { Specific gravity of coarse aggregate }=\left(\mathrm{W}_{\text {agg }}\right) /\left(\mathrm{W}_{\text {WATER }}\right) \\
& =4 / 1.625 \\
& =2.46 .
\end{aligned}
$$

\section{Free moisture test of fine aggregate}

Sample weight $=500 \mathrm{~g}$

Air dried weight $=489 \mathrm{~g}$

Free moisture content $(\%)=(500-489) /\left(500^{\star} 100\right)=2.2 \%$.

Sieve analysis of fine and coarse aggregate: The sifter examination, usually known as the degree test, is a fundamental thing test for every total expert. The strainer examination decides the degree (the circulation of total particles, by measure, inside a given example) keeping in mind the end goal to decide consistence with outline, generation control prerequisites, and confirmation particulars. The degree information might be utilized to ascertain connections between different total or total mixes, to check consistence with such mixes, and to foresee patterns amid creation by plotting degree bends graphically, to give some examples employments. Utilized as a part of conjunction with different tests, the sifter investigation is a decent quality control and quality acknowledgment instrument (Figures 1-3; Tables 1 and 2).

The apparatus used are:

1. A set of IS Sieves of sizes: $80 \mathrm{~mm}, 63 \mathrm{~mm}, 50 \mathrm{~mm}, 40 \mathrm{~mm}, 31.5$ $\mathrm{mm}, 25 \mathrm{~mm}, 20 \mathrm{~mm}, 16 \mathrm{~mm}, 12.5 \mathrm{~mm}, 10 \mathrm{~mm}, 6.3 \mathrm{~mm}, 4.75 \mathrm{~mm}, 3.35$ $\mathrm{mm}, 2.36 \mathrm{~mm}, 1.18 \mathrm{~mm}, 600 \mu \mathrm{m}, 300 \mu \mathrm{m}, 150 \mu \mathrm{m}$ and $75 \mu \mathrm{m}$.

2. Balance or scale with an accuracy to measure 0.1 percent of the weight of the test sample.

Free moisture test of coarse aggregate:

Weight of wet aggregate $(W)=1.017 \mathrm{~kg}$

Weight of dry aggregate $(\mathrm{d})=1 \mathrm{~kg}$ 
$=(1.017-1) / 1.017^{\star} 100=1.67 \%$.

\section{Water absorption of coarse aggregate}

Weight of sample $\left(\mathrm{W}_{1}\right)=1 \mathrm{~kg}$

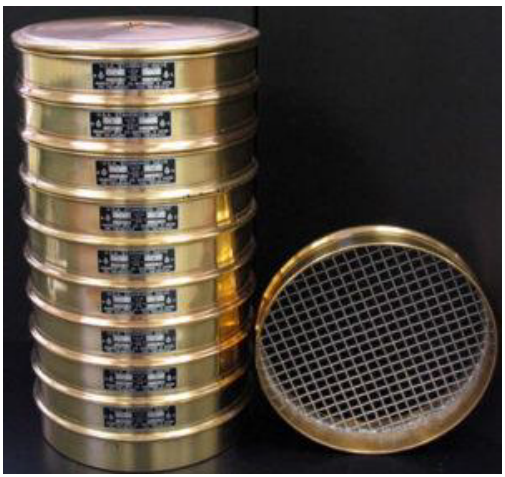

Figure 1: Sieve analysis of fine aggregates.

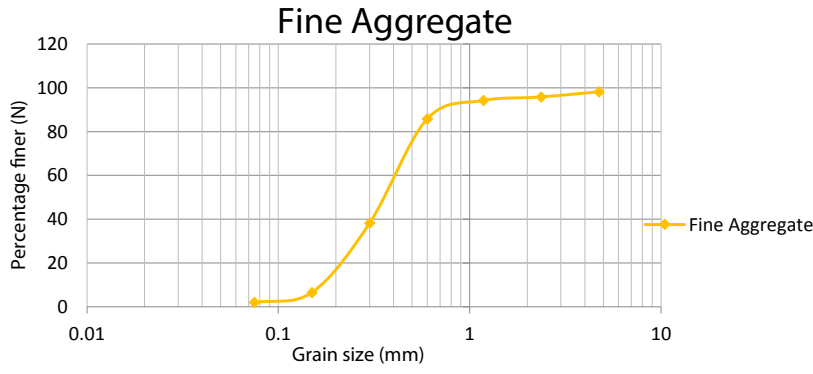

Figure 2: Graph of fine aggregates.

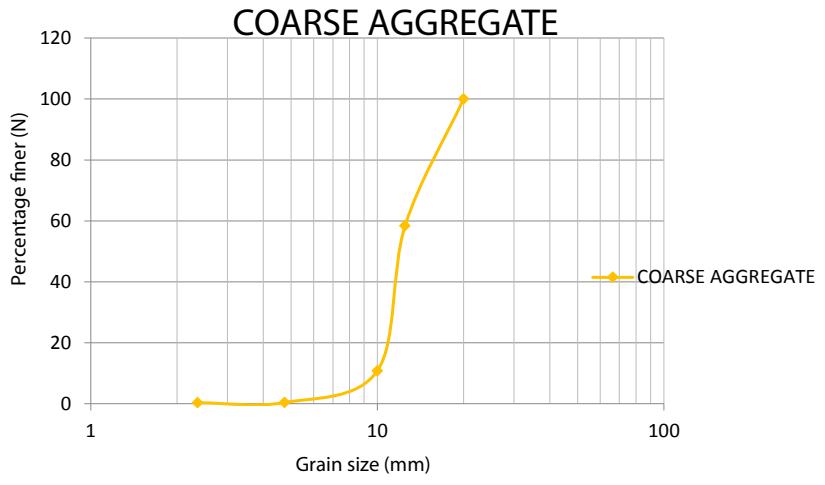

Figure 3: Graph of coarse aggregate.
Free moisture content $(\%)=(\mathrm{W}-\mathrm{d}) /\left(\mathrm{W}^{\star} 100\right)$

weight of aggregate water $\left(\mathrm{W}_{2}\right)=1.018 \mathrm{~kg}$

Weight of oven dried aggregate $\left(\mathrm{W}_{3}\right)=0.997 \mathrm{~kg}$

Water absorption $(\%)=\left(\mathrm{W}_{2}-\mathrm{W}_{3}\right) /\left(\mathrm{W}_{3}{ }^{\star} 100\right)=2.1 \%$

Water absorption of fine aggregate

Weight of sample $\left(\mathrm{W}_{1}\right)=1 \mathrm{~kg}$

Weight of aggregate water $\left(\mathrm{W}_{2}\right)=1.018 \mathrm{~kg}$

Weight of oven dried aggregate $\left(\mathrm{W}_{3}\right)=0.997 \mathrm{~kg}$

Water absorption $=(1.018-0.997) /(0.997) * 100=2.1 \%$.

Specific gravity of cement

The specific gravity of cement used $=3.15$

\section{Slump test}

Slump value $=110 \mathrm{~mm}$ (Figure 4).

Mix proportions for M25: After following the step by step procedure laid down in IS 10262:2009 and calculating various parameters, the following result was obtained:

\section{Cement $=465 \mathrm{~kg}$}

Water $=213 \mathrm{~kg}$

Coarse aggregate $=1115 \mathrm{~kg} / \mathrm{m}^{3}$

Fine aggregate $=549.93 \mathrm{~kg} / \mathrm{m}^{3}$

Water-cement ratio $=0.45$.

Compressive testing: To test for characteristics strength of the M25 grade of concrete, 6 concrete cubes are cast in $150 \mathrm{~mm} \times 150$ $\mathrm{mm} \times 150 \mathrm{~mm}$ size cubes and put in water for curing up to 28 days. After 7 -days of curing 3 cubes are removed and tested for compressive strength and the mean of the 3 results is considered and after 28-days the rest of the 3 cubes are also removed and tested for compressive strength and the mean of the 3 results is considered as well (Figure 5).

Flexural strength test: Is the measure of the tensile strength of concrete. It is a measure of an unreinforced concrete beam or slab to resist failure in bending (Figures 6 and 7).

\section{Results and Discussions}

This sections presents the results of the compressive tests performed on the casted concrete cubes and the beams with their respective percentage of fiber content. The tests were conducted for 7 th and 28th day, in which the percentage of fiber is based on the volume of cubes as well as beam.

\section{Compressive strength test result}

Table 3 shows the various compressive strengths obtained as the

\begin{tabular}{|c|c|c|c|c|c|}
\hline S/no & IS sieve size $\mathrm{mm}$ & Wt. retained in sieve gm & $\%$ retained On sieve & Cumulative $\%$ Retained in sieve & $\%$ finer \\
\hline 1 & 4.75 & 0.009 & 1.8 & 1.8 & 98.2 \\
\hline 2 & 2.36 & 0.012 & 2.4 & 4.2 & 95.8 \\
\hline 3 & 1.18 & 0.008 & 1.6 & 5.8 & 94.2 \\
\hline 4 & $600 \mu \mathrm{m}$ & 0.042 & 8.4 & 14.2 & 85.8 \\
\hline 5 & $300 \mu \mathrm{m}$ & 0.238 & 47.6 & 61.8 & 38.2 \\
\hline 6 & $150 \mu \mathrm{m}$ & 0.158 & 31.6 & 93.4 & 6.6 \\
\hline 7 & $75 \mu \mathrm{m}$ & 0.023 & 4.6 & 98 & 2 \\
\hline 8 & Pan & 0.010 & 2 & 100 & 0 \\
\hline
\end{tabular}

Table 1: Sieve analysis of fine aggregate. 
Citation: Bashir A, Gupta C, Abubakr MA, Abba SI (2018) Analysis of Bamboo Fibre Reinforced Beam. J Steel Struct Constr 4: 146. doi: 10.4172/24720437.1000146

Page 4 of 6

\begin{tabular}{|c|c|c|c|c|c|}
\hline S/no & IS sieve size Mm & Wt. retained in sieve gm & \% retained On sieve & Cumulative \% Retained in sieve & \% finer \\
\hline 1 & 20 & 0 & 0 & 0 \\
\hline 2 & 12.5 & 2.081 & 41.62 & 41.62 \\
\hline 3 & 10 & 2.380 & 47.60 & 89.22 \\
\hline 4 & 4.75 & 0.519 & 10.38 & 9.38 \\
\hline 5 & 2.36 & 0.004 & 0.08 & 9.60 \\
\hline 6 & Pan & 0.013 & 0.26 & 0.4 \\
\hline
\end{tabular}

Nominal size of aggregate $=20 \mathrm{~mm}$

Table 2: Sieve analysis of coarse aggregate.

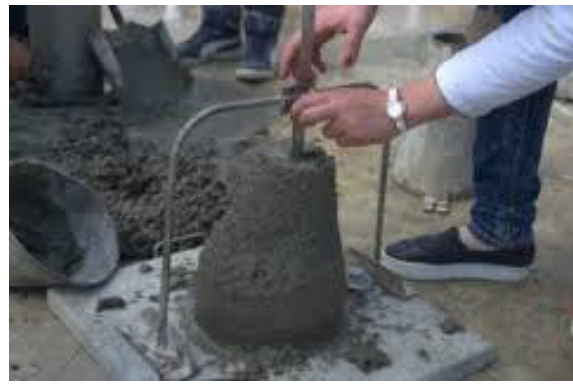

Figure 4: Slump test.

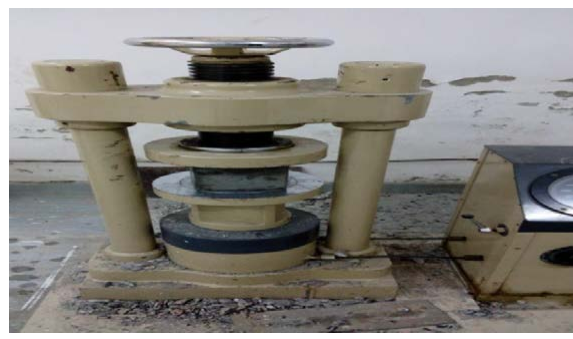

Figure 5: Compression testing machine

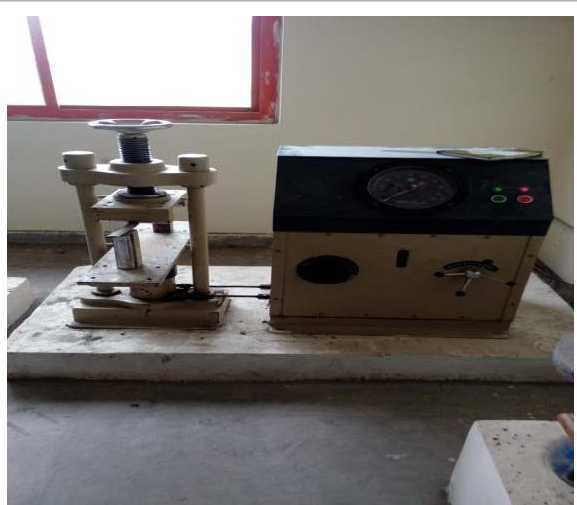

Figure 6: Flexural testing machine. Depicts the flexural testing machine using which the flexural strength of the beam samples are tested. It uses a two point load test system on the beam.

value of the bamboo fiber percentage increased from $0 \%, 0.5 \%, 1 \%$, $1.5 \%$ and $2 \%$.

The readings indicated that as the percentage of fiber increases the compressive strength increases simultaneously with number of curing days (Figure 8).

Figure 9 shows that in both the 7-day and 28-day compressive strength test results, the compressive strength of the concrete cubes 7-day compressive Strength

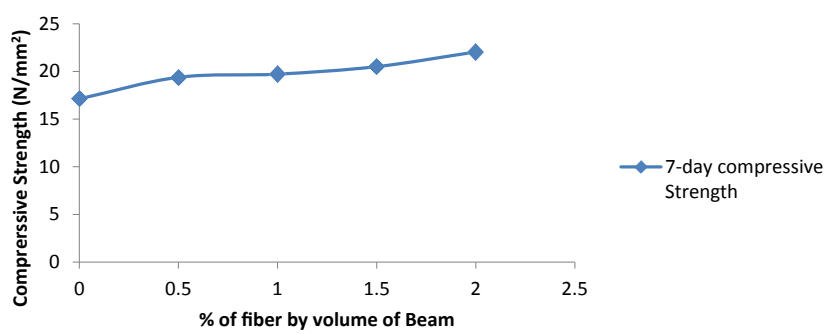

Figure 7: Graph of 7-day compressive strength

28-day Compressive Strength

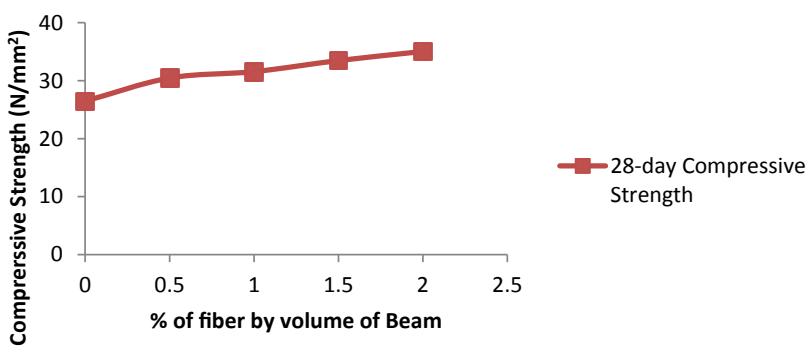

Figure 8: Graph of 28-day compressive strength.

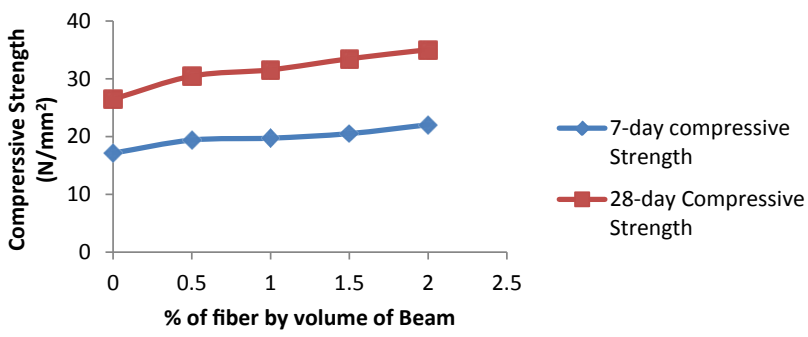

Figure 9: Comparison between 7-day and 28-day compressive strength.

increased which indicates that the bamboo fibers had some positive impact on the compression resistance of the concrete.

\section{Flexural strength test results}

Figures 10-12 show that, the flexural strength of both the 7-day and 28-day flexural strength results obtained reduces as the bamboo fiber percentage increases which clearly suggest that bamboo fiber has negative impact on the beams. Unlike the bamboo stick which produces positive impact on the flexural strength of the beams when used as reinforcement, the bamboo fibers do not (Table 4). 


\begin{tabular}{|c|c|c|c|c|}
\hline \multirow[t]{2}{*}{ Series } & \multirow{2}{*}{$\begin{array}{c}\text { Fiber content } \\
(\%)\end{array}$} & \multirow[t]{2}{*}{ No. of cubes } & \multicolumn{2}{|c|}{ Compressive strength $\left(\mathrm{N} / \mathrm{mm}^{2}\right)$} \\
\hline & & & 7 day & 28 day \\
\hline 1 & 0 & 6 & 17.13 & 26.47 \\
\hline 2 & 0.5 & 6 & 19.39 & 30.46 \\
\hline 3 & 1.0 & 6 & 19.72 & 31.56 \\
\hline 4 & 1.5 & 6 & 20.51 & 33.47 \\
\hline 5 & 2 & 6 & 22.05 & 35.04 \\
\hline
\end{tabular}

Table 3: Average compressive strengths of cubes samples.

\begin{tabular}{|c|c|c|c|c|}
\hline \multirow[t]{2}{*}{ S/no } & \multirow[t]{2}{*}{ Fiber content (\%) } & \multirow[t]{2}{*}{ No of Beams } & \multicolumn{2}{|c|}{ Flexural strength $\left(\mathrm{N} / \mathrm{mm}^{2}\right)$} \\
\hline & & & 7 day & 28 day \\
\hline 1 & 0 & 6 & 1.5 & 2.5 \\
\hline 2 & 0.5 & 6 & 1.2 & 2.13 \\
\hline 3 & 1 & 6 & 1 & 2 \\
\hline 4 & 1.5 & 6 & 0.8 & 1.88 \\
\hline 5 & 2 & 6 & 0.7 & 1.65 \\
\hline
\end{tabular}

Table 4: Comparison between the 7-day and 28-day flexural strength results.

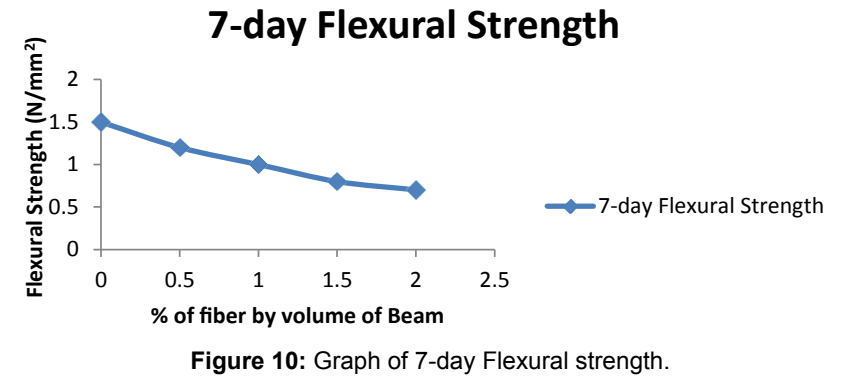

28-day Flexural strength

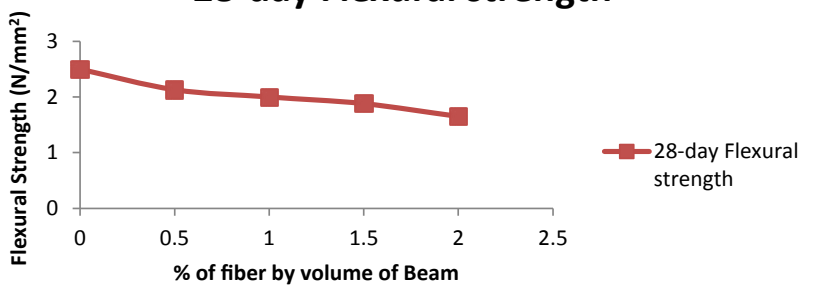

Figure 11: Graph of 28-day Flexural strength.

\section{Conclusion}

Worry for condition and regular assets have expanded amid the most recent couple of decades. It has come to see that exorbitant or inadequate utilization of characteristic assets is in certainty a mishandle to the earth. Appropriate comprehension of supportability in building development has experienced immense changes in the ongoing years. Prior consideration was given just to specialized issues of designing structures however as time advances non-specialized issues, for example, economy, social sustainability came into picture drastically. Bamboo fiber reinforced concrete stands to be a good option in the sustainable development of civil engineering construction. Many researches' have been carried out in this field which helps us in understanding that use of bamboo in reinforced concrete has a vast scope. And this research aims at find out the possible impact of bamboo fiber on the compressive as well as flexural strength of concrete beam.

Based upon the tests conducted, the following conclusions are at the forefronts:

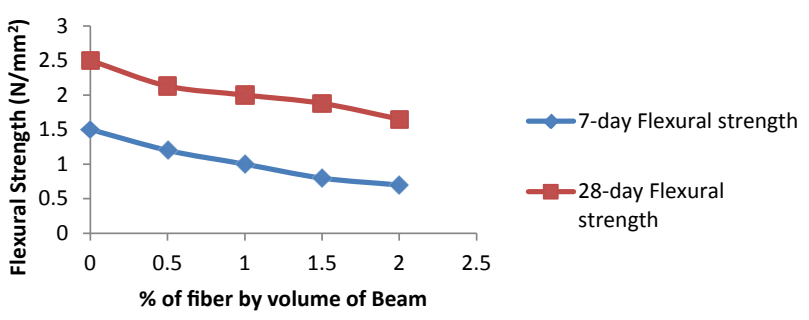

Figure 12: Comparison between the 7-day and 28-day flexural strength results.

1. The compressive strength of concrete increases as we increase the fiber percentage.

2. The flexural strength decreases as the percentage of fiber increases.

3. The disappointment loads differed with the pressure quality of the solid, giving a lower disappointment load to bring down pressure qualities [15-20].

Therefore, bamboo fibers can be used to increase the compressive strength of concrete structures keeping in mind that it reduces the flexural strength of the structures.

\section{Recommendations}

1. This project suggests many recommendations for future research.

2. Different clear cover dimensions are suggested to be used. The cover used is based on protecting steel from corrosion. Since Bamboo does not corrode in concrete, the cover could potentially be less.

3. Beam tests with different percentage of Bamboo reinforcement should be investigated.

4. An extensive study to evaluate the behavior of different types of bamboo is recommended as the bamboo type and behavior is different at different regions of the world.

5. Low frequency fully cyclic experimental tests could be conducted to identify the behavior of Bamboo reinforced concrete in earthquake induced ground acceleration 
6. Pressure treatment of Bamboo is suggested before conducting four-point bending tests to provide a greater Bamboo strength.

7. Long-term studies investigating the durability of Bamboo reinforced concrete should be conducted.

8. The effect of thickness on the strength of bamboo tensile samples is suggested to be investigated by conducting tensile tests on samples with the same dimensions as those used in concrete.

9. Variation of Bamboo tensile specimen length is suggested to determine if this is a factor for tensile strength.

10. More tensile tests is suggested to investigate the relationship between the tensile strength of bamboo and its performance as reinforcement in concrete.

\section{References}

1. Ghavami K (2004) Bamboo as Reinforcement in Structural Concrete Elements. Cement \& Concrete Composites, 27: 637-649.

2. Amada S, Untao S (2001) Fracture Properties of Bamboo. Composites Part B Engineering, 32: 451-459.

3. Steinfeld C (2001) A Bamboo Future. Environmental Design and Construction, pp: $1-5$.

4. Amada S, Ichikawa Y, Munekata T, Nagase Y, Shimizu H (1997) Fiber Texture and Mechanical Graded Structure of Bamboo. Composites Part B Engineering, 28: $13-20$

5. IS 10262.2009 concrete mix proportions.

6. IS 456.2000 plain concrete designs.
7. IS 383 (1970) Specification for Coarse and Fine Aggregates From Natural Sources For Concrete [CED 2: Cement and Concrete].

8. Ghavami K (1995) Ultimate Load Behavior of Bamboo-Reinforced Lightweigh Concrete Beams. Cement \& Concrete Composites, 17: 281-288.

9. INBAR (2002) (International Network for Bamboo and Rattan) Bamboo Structure at CO: Advantages and Disadvantages.

10. Projects on Bamboo Structures at the Technical University of Eindhoven (2002) INBAR (International Network for Bamboo and Rattan).

11. Bamboo in Construction: An Introduction (INBAR 2004) (International Network for Bamboo and Rattan)

12. Bamboo Structural Design (ISO 1999) (International Standard Organization)

13. ISO (1999) Determination of Physical and Mechanical Properties of Bamboo.

14. DIS-22157 (International Standard Organization) 85

15. ISO (International Standard Organization) (1999) Laboratory Manual on Testing Methods for Determination of Physical and Mechanical Designing and Building with Bamboo, TC 165 N315.

16. Janseen JA (2000) Designing and Building with Bamboo. International Network for Bamboo and Rattan, ISBN 81-86247-46-7.

17. Tommy YL, Cui HZ, Leung HC (2004) The Effect of Fiber Density on Strength Capacity of Bamboo. Materials Letter, 58: 2595-2598.

18. Mardjono F (2001) Bamboo knowledge based building design decision support system. In conference; Annual Conference of the Research School Structura Engineering.

19. Masani NJ, Dhamani BC, Singh B (1977) Studies on Bamboo Concrete Composite Construction.

20. Francis EB, Paul JR (1996) Bamboo Reinforced Concrete Construction. US Naval Civil Engineering Laboratory, pp. 1-19. 